THE HANSEN REPORT IN THE SPOTLIGHT

\title{
A Paradigm Shift in Chin
The New Powertrain Mix
}

The Chinese market has been regarded throughout the world as leading the way in electric mobility. However, in the future the Chinese regime

will be putting greater emphasis on other types of powertrain. This new trend cannot fail to have an impact on European manufacturers and markets.

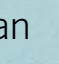
ts

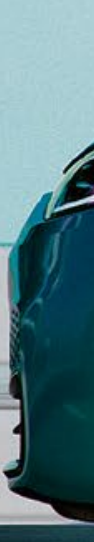

(4) 


\section{CHINA IN A STATE OF CHANGE}

Over recent years, China has become the driving force behind the global automotive industry. The country's huge, flourishing market, combined with almost unbridled consumer spending as a result of its new prosperity, has seen its sales figures constantly rising. Although market growth began to slow in 2018 and 2019, with the numbers of new vehicle registrations well below the previous year, the forecast for the medium and long term, in particular in comparison with the USA and Europe, remains positive. One cornerstone of the Chinese mobility strategy was and still is the electric drive. China has promoted electric vehicles for three different reasons: firstly to reduce its dependency on crude oil, secondly to cut air pollution and thirdly to gain a technological advantage over the gasoline and diesel engines produced by the established markets.

The strategy has not yet paid off, at least with regard to the dependency on oil. The country's economic boom has forced the Chinese government to rely on oil imports since the end of the 1990s in order to satisfy the growing demand for energy. Throughout this period it has been trying in vain to reduce the amount being brought into the country. Currently China imports around $70 \%$ of its oil. Many of the regions that supply oil to China are politically unstable. In the event of a conflict, for example in the Middle East, around $50 \%$ of the oil imports could be put seriously at risk within a matter of only days or weeks. As a result, in the 1990 s the regime came up with the idea of generating electricity from domestically produced coal to power electric vehicles. During the years after the decision was made, some initial research and development was carried out and this was followed by a large number of implementation projects.

\section{STATE REGULATIONS}

At the same time a whole raft of state regulations was introduced. The legislation often did not remain in force for long and was generally amended every six months. The key regulations to emerge over the last few years have been the New Energy Vehicle (NEV) policy and the even more important fleet consumption target or Corporate Average Fuel Consumption (CAFC).

The NEV policy is a complex bonus system which involves awarding credits and allows certain vehicles to be counted more than once. Initially, battery electric and fuel cell vehicles, together with plug-in hybrids, were considered to be compliant with the NEV regulations. "After the bonus system was introduced, it became clear over time that manufacturers were putting too much emphasis on the NEV regulations and that there had been an overall increase in the fuel consumption of vehicles with combustion engines," explains Nicole Steiger from JSC Automotive, a strategic consultancy company that specializes in the Chinese automotive market. The new version of the regulations, which came into effect in mid 2019, capped the NEV subsidies at $75 \%$. In addition, local government bodies were banned from introducing their own subsidy programs. This had a dramatic impact on vehicle prices and also on sales, in particular of plug-in hybrids. "We believe that the Chinese government recognized that there will still be vehicles with combustion engines on 


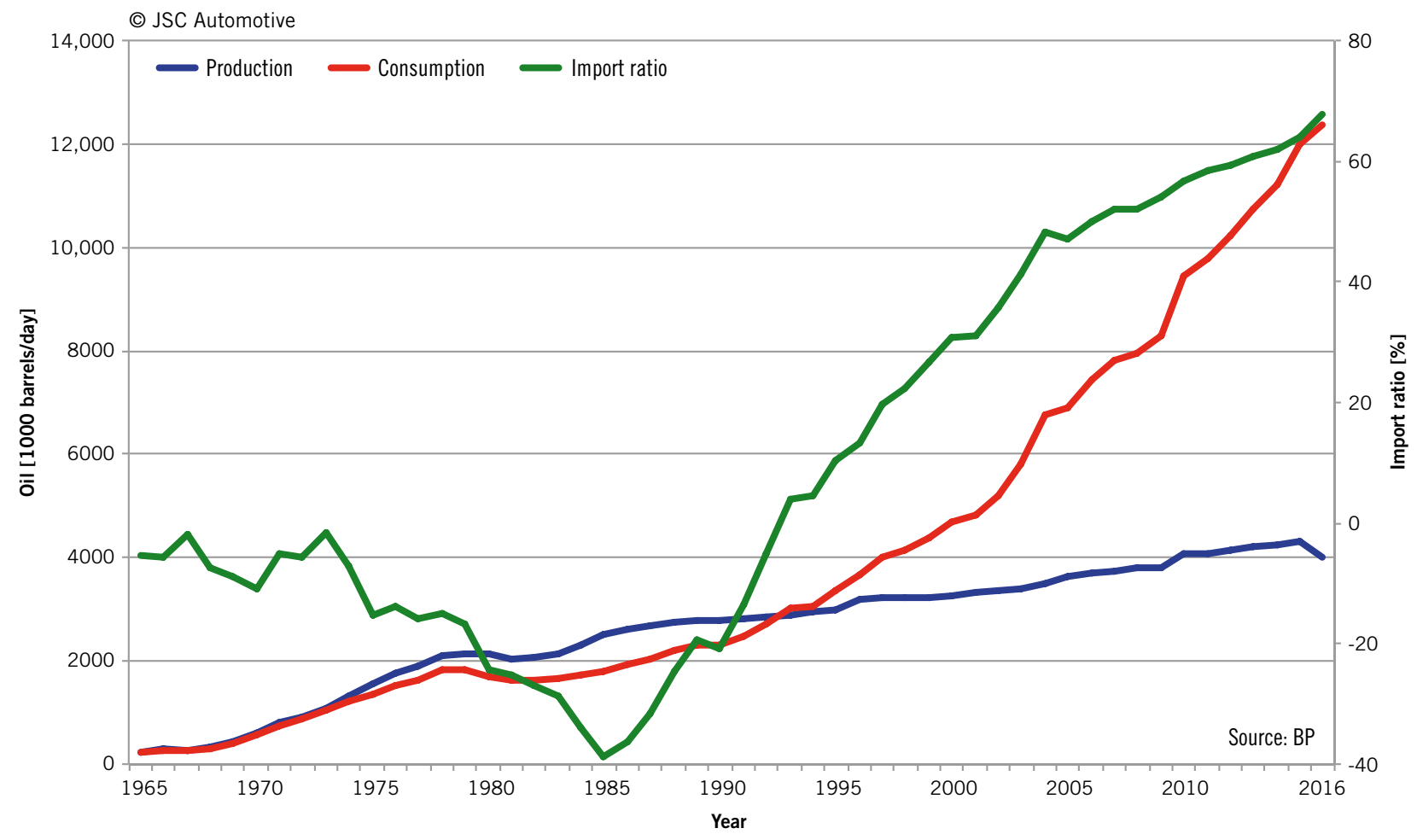

China is heavily dependent on oil imports

the roads for some time and that it makes sense to encourage manufacturers to reduce the fuel consumption of these vehicles. That's the background to the change in the regulations in China last year," says Jochen Siebert, one of Steiger's colleagues. This assessment is also supported by the fact that although the Chinese government has now extended the NEV subsidies, which were originally only planned until the end of 2020, to 2022 [1], the amount has been successively reduced - by $10 \%$ annually - and limited to vehicles up to a price of 300,000 Yuan. Ultimately, this makes the subsidy even less attractive.

In 2019 the government in Beijing also introduced an additional certification category for Low Fuel Consumption Vehicles (LFCVs), alongside vehicles with conventional combustion engines and NEVs. The category includes vehicles with an actual fuel consumption that falls below the target. This depends on the gross vehicle weight and the number of rows of seats. By producing LFCVs, manufacturers can halve the number of bonus points they need to fulfill the government quota of NEVs. As a result, the new LFCV regulations will further limit the market prospects of Battery Electric Vehicles (BEV). "In many cases it is cheaper for manufac- turers to produce LFCVs rather than BEVs or plug-in hybrids," says Steiger. This is because, as things stand, it is the state regulations and not the demand from the market that determine the production figures for BEVs in China. "We have based our scenario on the assumption that this won't change until after 2025. At least in the medium term, the volume of BEVs will still be decided by the CAFC regulations and the NEV quota," explains Siebert.

Experts expect the requirements of the CAFC regulations to be harder to meet than the NEV. They believe that the manufacturers will concentrate on it for this reason and will aim to achieve the NEV quota in passing. "All the manufacturers are likely to choose the cheapest option. For Chinese companies, this means moving more engines over to direct injection or turbocharging. Manufacturers in the higher price segment will increasingly be considering 48 -V systems. Another interesting consideration is that methanol vehicles also count as LFCVs, according to the Chinese Ministry of Industry and Information Technology," comments Steiger. Over the last five years, China has replaced around $15 \%$ of the fuel produced from crude oil with methanol deriva- tives. Roughly two thirds of the methanol is manufactured in chemical plants where coal is used as the raw material.

At the same time as relaxing the NEV regulations, the government in Beijing is attempting to reduce the country's dependency on imported oil at least to a certain extent by making the CAFC regulations more stringent. For example, from 2020 fleet consumption will be restricted to 51 per $100 \mathrm{~km}$ and in 2025 this figure will be reduced by a further $20 \%$. In addition, from 2025 the $\mathrm{CO}_{2}$ emissions of electric vehicles will be included in full in this calculation by means of an equivalence mechanism. "This will make electric vehicles even more unattractive for manufacturers. There will also be no more NEV quotas, which means that electric cars will finally be forced to prove themselves on the market without the specific advantages provided by the regulators," says Steiger, summing up the situation.

\section{SMALL MANUFACTURERS PARTICULARLY HARD-HIT}

The reduction in the subsidies offered by the Chinese state is hitting the many small start-up manufacturers without adequate financial backing particularly 


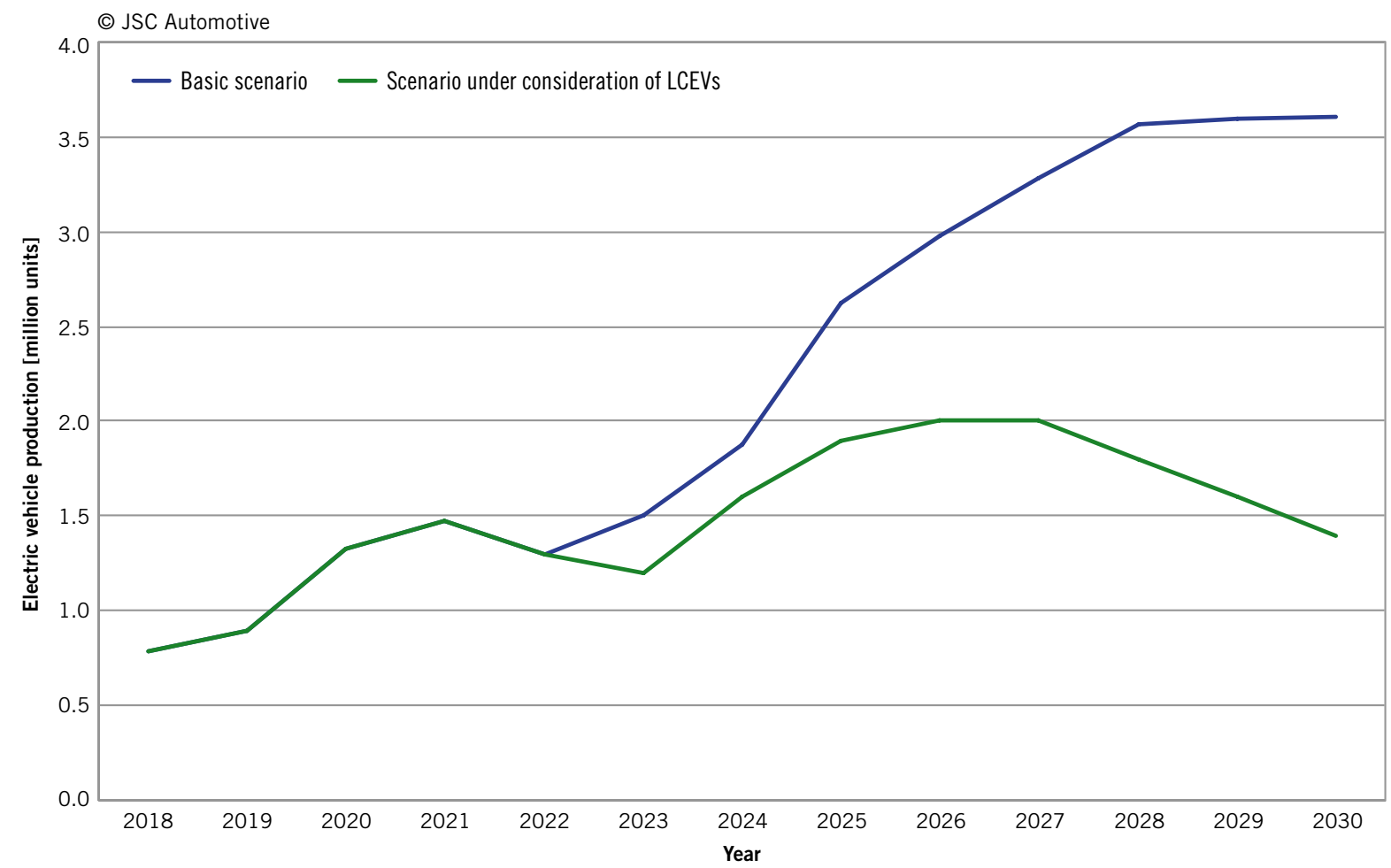

Electric vehicle production in China based on previous regulations and the new LFCV policy

hard. Industry experts believe that up to 500 companies will not survive this consolidation process. By contrast, the large, established carmakers have long since incorporated the changes into their plans and will even benefit from them. "State subsidies for electric cars are a good way of stimulating the market. But in the long term we need a healthy market

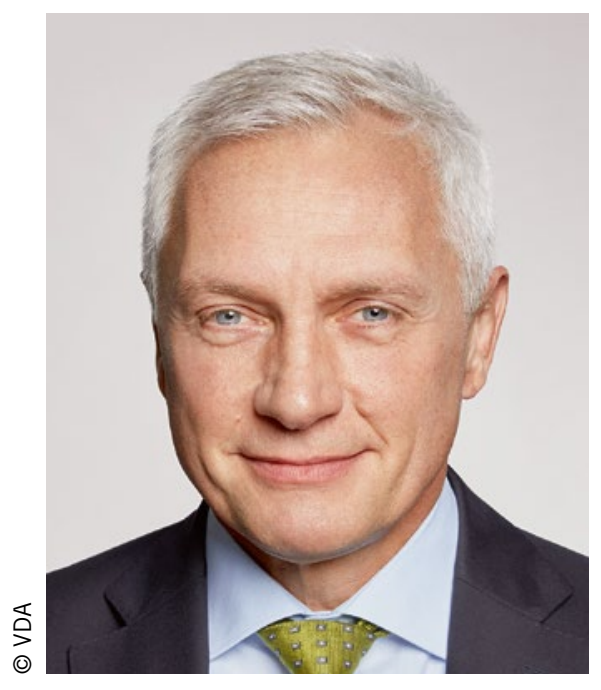

Dr. Joachim Damasky

Managing Director of the German Association of the Automotive Industry (VDA) for electric vehicles without this kind of financial incentive. For this reason, our electrification strategy has not been based on the expectation of subsidies," explains Dr. Stephan Wöllenstein, CEO of Volkswagen Group China. Volkswagen sees the Chinese market as being the powerhouse of the global automotive industry. It determines the direction of trends such as electric mobility and digitalization. "Volkswagen Group China and our activities on the Chinese market play an important role in the group's global electric strategy. One important milestone this fall is the start of local production of the modular platform for fully electric cars (MEB) at two new plants in Anting and Foshan with an annual capacity of

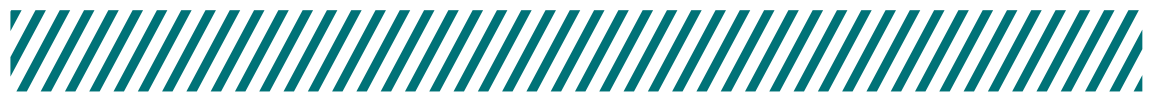 2 QUESTIONS FOR ...}

How important is the Chinese market for electric vehicles to the automotive industry in Germany? DAMASKY _ The Chinese electric vehicle market offers a great deal of potential for German carmakers and their suppliers. In 2019 it was by far the largest market for electric cars in the world. The German manufacturers' share of the electric vehicle market in China has recently grown significantly. It amounted to $7 \%$ in 2019 and this figure is increasing. However, we should not attach too much importance to the current German market share of $12 \%$, which is relatively high. The
Chinese market was hard hit by the coronavirus pandemic in the first quarter and has not yet recovered.

\section{What impact will the ending} of the NEV subsidies in 2022 have on German manufacturers? DAMASKY_From an overall perspective, the end of the incentives will have a negative impact on the market. However, German carmakers' sales are likely to be less affected, because the NEV subsidies are currently mainly aimed at products from high-volume manufacturers. 


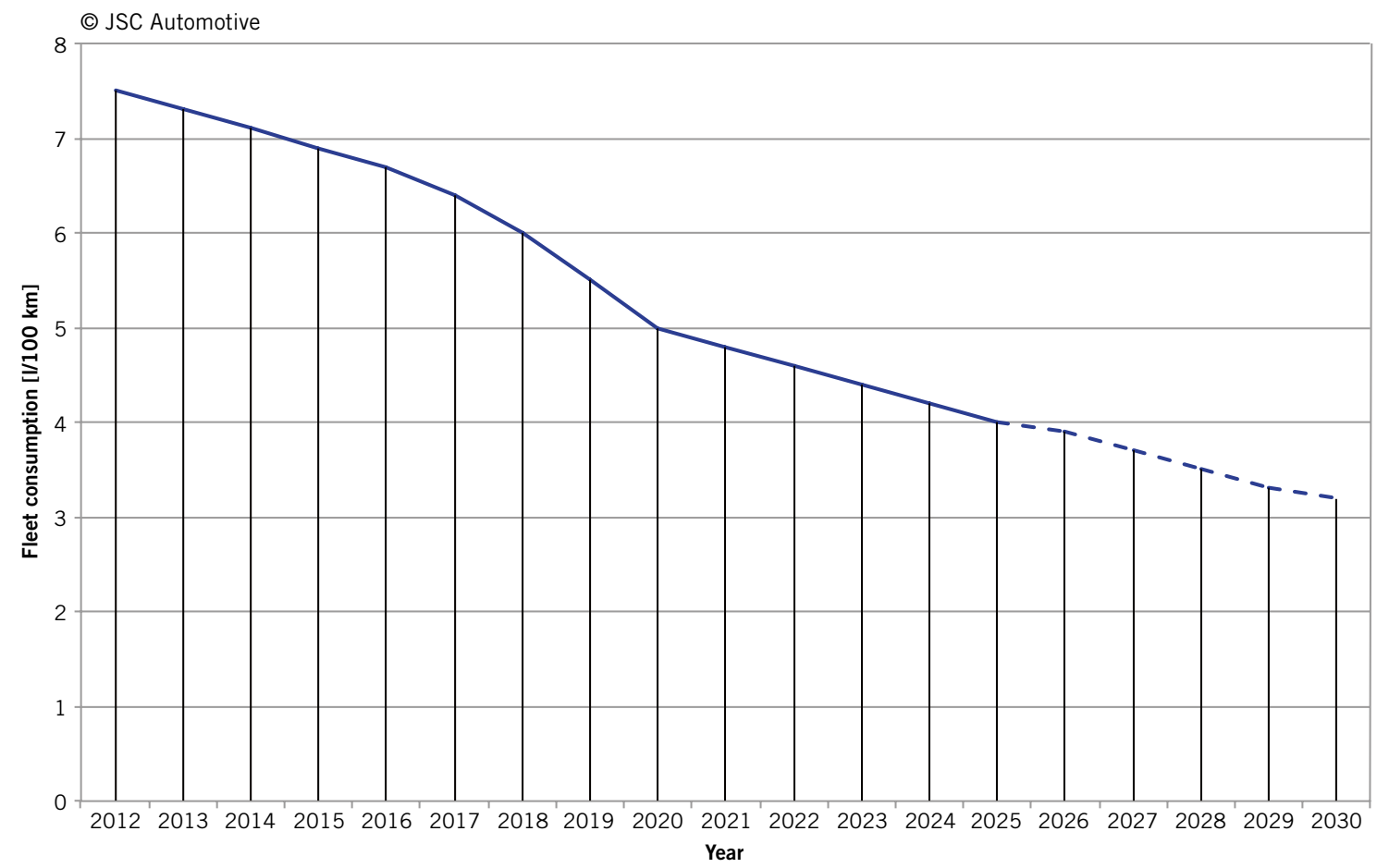

Thresholds for the CAFC regulations

600,000 units," says Wöllenstein. Volkswagen is currently planning to deliver around 1.5 million electric cars to Chinese customers in 2025. With the aim of maintaining the interest of Chinese car buyers in electric mobility, Volkswagen has spoken out in favor of an increased range of non-financial incentive packages, such as free parking, the use of bus lanes, easy electric charging and exemptions from driving bans in cities.

Development service providers, which can respond very flexibly to the changing conditions, are also taking a relaxed approach to the new direction of Beijing's strategy. "We always monitor the technological and legislative changes in China very carefully and regularly talk to our customers about them. Our customers' new vehicle projects not only include new powertrain solutions, but also overall concepts that increasingly reflect the changing behavior of Chinese drivers," explains Kurt Schwaiger, Managing Director of the Porsche Engineering subsidiary in Shanghai. "It's always important to look at developments from an overall perspective," he adds.

\section{EUROPE IS THE NEW LEAD MARKET}

As the focus moves away from battery electric powertrains in China, so the importance for the electric vehicle market of activities in other countries grows. The management consultancy firm McKinsey is predicting that Ger- man manufacturers' share in global electric vehicle production will increase from 18 last year to $29 \%$ in 2024 [2]. This means that Germany could become

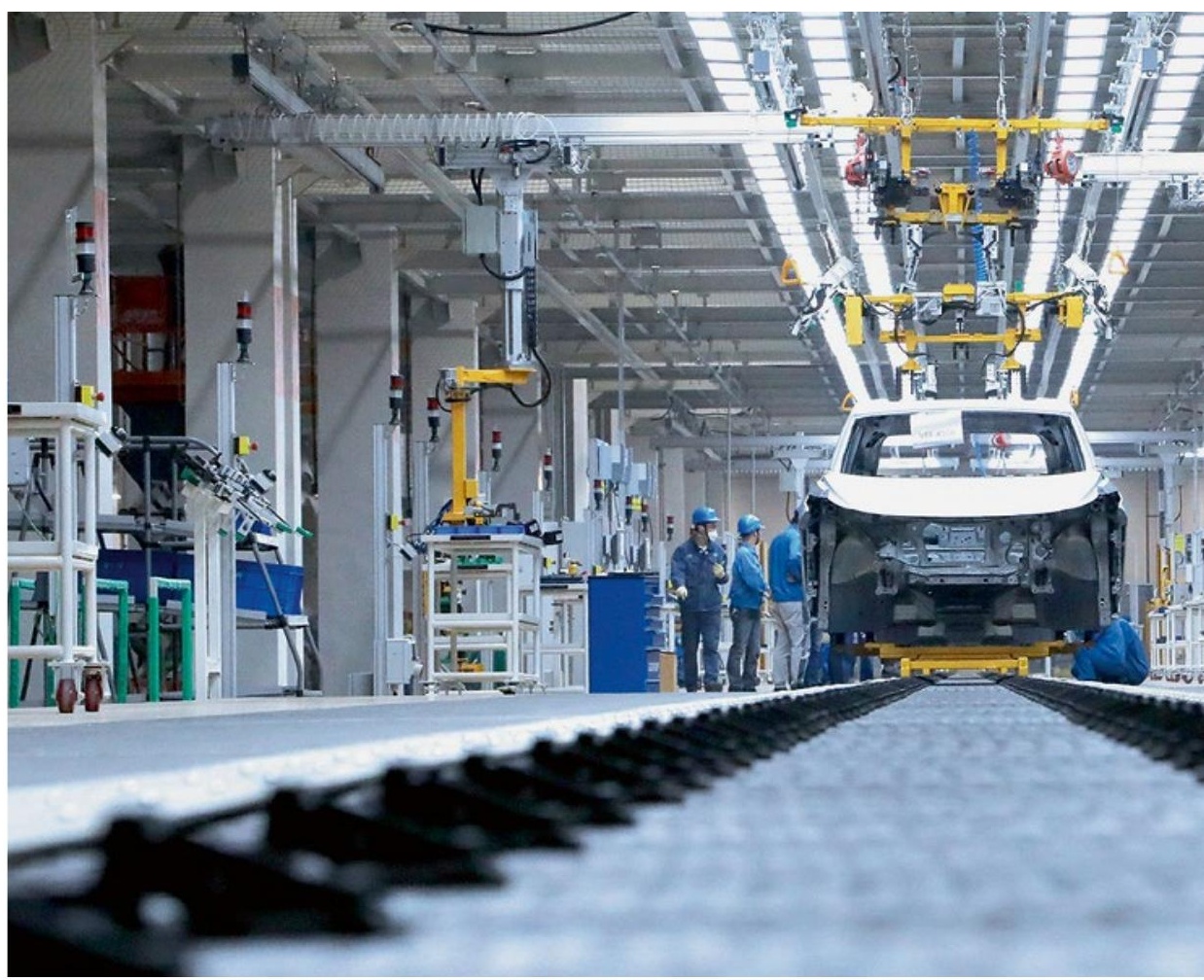

Start of pre-production of vehicles on the basis of the modular platform for electric cars (MEB) at Volkswagen's electric vehicle plant in Anting 
the global market leader for electric vehicles with 1.7 million units manufactured by 2021, relegating China to second place. "China will continue to be the largest market in the world and the range of locally produced products has increased significantly," says Nicolai Müller, senior partner at McKinsey in Cologne. "But demand in Europe has grown by leaps and bounds. We can expect more developments in the form of a growing range of products that will enable manufacturers to meet their $\mathrm{CO}_{2}$ targets." The total sales of electric cars and plug-in hybrids in Europe increased by $44 \%$ compared with the previous year to more than 600,000 vehicles. According to McKinsey, by 2021 manufacturers will need to sell more than 2 million electric vehicles in order to avoid paying fines to the EU. McKinsey's conclusion is that this will make Europe the future hot spot for electric mobility.

Richard Backhaus

\section{REFERENCES}

[1] Jian, Y.: Beijing extends subsidies, tax exemption for EVs; cuts VAT on used vehicles. Online: https:// www.autonews.com/china/beijing-extends-subsidies -tax-exemption-evs-cuts-vat-used-vehicles, access: May 13, 2020

[2] McKinsey (ed.): Electric Vehicle Index:

Europa wird zum Hotspot der Elektromobilität. Online: https://www.mckinsey.de/news/presse/

2020-03-02-evi-2020, access: April 8, 2020
1/////////////////////////////4

\section{WHAT DO WE THINK?}

"All too often the German automotive industry is unfairly accused of missing the boat when it comes to electric vehicles. Critics are fond of mentioning the rigidly controlled Chinese market while disregarding the coal-heavy energy mix and the democratic deficit. Objections based on the fact that battery electric powertrains are not the right solution for all types of mobility requirements have simply been dismissed as representing an attitude of denial. It will be interesting to hear what these people have to say when Europe becomes the lead market." 